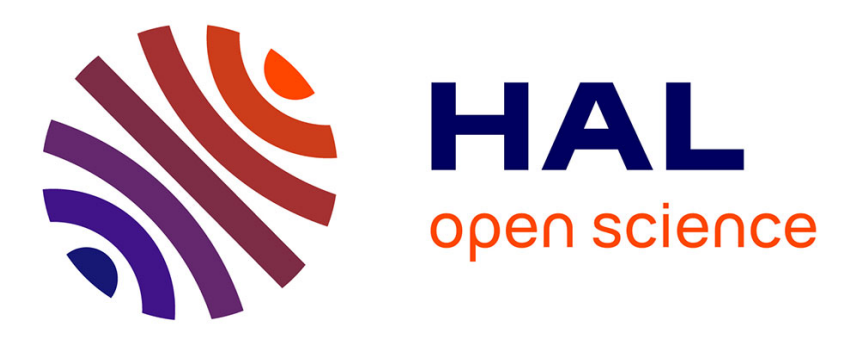

\title{
Suicidal thoughts and depressive feelings amongst Estonian schoolchildren: effect of family relationship and family structure
}

Algi Samm, Liina-Mai Tooding, Merike Sisask, Kairi Kõlves, Katrin Aasvee, Airi Värnik

\section{To cite this version:}

Algi Samm, Liina-Mai Tooding, Merike Sisask, Kairi Kõlves, Katrin Aasvee, et al.. Suicidal thoughts and depressive feelings amongst Estonian schoolchildren: effect of family relationship and family structure. European Child and Adolescent Psychiatry, 2009, 19 (5), pp.457-468. 10.1007/s00787-0090079-7 . hal-00540582

\section{HAL Id: hal-00540582 \\ https://hal.science/hal-00540582}

Submitted on 28 Nov 2010

HAL is a multi-disciplinary open access archive for the deposit and dissemination of scientific research documents, whether they are published or not. The documents may come from teaching and research institutions in France or abroad, or from public or private research centers.
L'archive ouverte pluridisciplinaire HAL, est destinée au dépôt et à la diffusion de documents scientifiques de niveau recherche, publiés ou non, émanant des établissements d'enseignement et de recherche français ou étrangers, des laboratoires publics ou privés. 


\title{
Suicidal thoughts and depressive feelings amongst Estonian schoolchildren: effect of family relationship and family structure
}

\author{
Algi Samm • Liina-Mai Tooding • Merike Sisask • \\ Kairi Kõlves $\cdot$ Katrin Aasvee $\cdot$ Airi Värnik
}

Received: 5 November 2008/ Accepted: 10 November 2009/Published online: 28 November 2009

(C) Springer-Verlag 2009

\begin{abstract}
Depressive feelings and suicidal ideation in a non-clinical sample of adolescents in Estonia were analysed in the context of family structure, mutual relationships amongst family members and schoolchildren's preferences regarding intimate personal contacts with particular family members. Data from the WHO collaborative study 'Health Behaviour in School-aged Children 2005/ 2006' (HBSC) were used. A representative sample of schoolchildren aged 11, 13 and 15 years completed the semi-structured questionnaire. The analyses included only adolescents living in households with at least one birth parent. The subjects were 4,389 schoolchildren ( 2,178 boys and 2,211 girls), who were divided into three groups based on: (1) suicidal thoughts, with or without depressive feelings; (2) depressive feelings; and (3) neither suicidal thoughts nor depressive feelings. Multinomial logistic regression was used. The proportion of depressive feelings increased with age for both boys and girls. Girls expressed depressive feelings more frequently than boys from ages 13
\end{abstract}

A. Samm · L.-M. Tooding · A. Värnik

Faculty of Social Sciences, University of Tartu,

Ülikooli 18, 50090 Tartu, Estonia

A. Samm $(凹) \cdot$ M. Sisask · K. Kõlves · A. Värnik

Estonian-Swedish Mental Health and Suicidology Institute,

Õie 39, 11615 Tallinn, Estonia

e-mail: algi.samm@mail.ee

M. Sisask · A. Värnik

Tallinn University, Tallinn, Estonia

K. Kõlves

Australian Institute for Suicide Research and Prevention

(AISRAP), Griffith University, Brisbane, Australia

K. Aasvee

National Institute for Health Development, Tallinn, Estonia and 15 years, and suicidal thoughts from age 15 years. Self-reported satisfaction with relationships in the family reduced the likelihood of depressive feelings and suicidal thoughts. Good communication with the parents reduced the likelihood of suicidal thoughts in all age groups. Adolescents who were satisfied with their family relationships suffered less frequently from depressive feelings and suicidal thoughts. The best environment for an adolescent was a family with both birth parents. Of the adolescents in 'non-intact' families, those with a step-parent in the family showed suicidal thoughts more frequently than those in single-parent families. Associations between family-related variables and suicidal thoughts were significant even after adjusting for family economic deprivation score.

Keywords Depressive feelings - Suicidal thoughts . Adolescent - Relationships in family .

Economic deprivation

\section{Introduction}

Most of the authors describe suicide as a process gradually increasing from weariness of life to a desire to die, suicidal thoughts, suicide attempts and suicide. Suicidal behaviour is frequently associated with depression [1-3]. Descriptive epidemiology of children's and adolescents' suicidal behaviour shows, in a non-clinical sample of schoolchildren, self-reported suicidal ideation in approximately $1-14 \%$, and depressive symptoms in $18-44 \%$ of cases [4-7]. The risk of developing suicidal behaviour is thought to be associated with cumulative exposure to a range of factors: social and family circumstances, personality, traumatic life experiences and mental health $[3$, 8-15]. 
Depression impacts negatively growth and development, school performance, peer or family relationship and may lead to suicide [16]. Cognitive distortions are associated with depression. Depressed individuals have been shown to have a negative view of self, their current environment and the future [17]. Symptom expression may vary depending on the stage of development, and some adolescents may have difficulty identifying and describing internal mood stages [16]. To differentiate depression from normal variance in the mood of adolescents, clinical depression is associated with functional impairment. It is mediated through intensity, duration and lack of responsiveness of depressed mood and associated symptoms, and it is described as a change from prior behaviour [17].

To explain characterising depression, Wasserman indicated the importance of the complicated interplay between the individual, his unique personal history, inherited biological determinants and how these factors are modified by the psychosocial environment [18]. A thorough review by Zalsman et al. on topics of depressive disorder in children and adolescents shows that developmental factors contributing to an increased risk of depression include family discord, parental psychopathology, mental illness, experimentation with tobacco, drugs and alcohol, and decreased adult supervision and communication [17]. Social support serves as a buffer against the negative impact of life stress.

Children's vulnerability to suicidal behaviour depends heavily on the interactive effects within the family [19]. Children and adolescents who are dissatisfied with their social support tend to suffer from depressive symptoms $[20,21]$, and low family support is a predictor of adolescents' suicide attempts [22]. Family resources are often seen in terms of relationships between parents and children, but the importance of other supportive relationships (grandparents, siblings) has also been described [23, 24].

Previous studies have documented the adverse effects of changes in family structure on children's well-being, and pointed out that, compared with children brought up in intact families with two birth parents, children whose family structure is weaker are more likely to have emotional and psychological problems [25]. The prevalence of behavioural and emotional symptoms is lowest in children living with both their birth parents and highest amongst children living away from their biological parents [26]. Suicidality emerges as a result of complex interaction amongst social factors, childhood care and the influence of living in a single-parent home [27]. Children in lone-parent families and stepfamilies are at a disadvantage, in cognitive, emotional and behavioural terms, compared with those in two-parent families $[12,25]$. Previous findings indicated to mechanisms that connected mental health to the economic status of an adolescent $[9,28]$. Poor self- rated mental health and multiple health complaints are more common in lower socio-economic groups [29].

Sabbath indicates that the voluntary act of taking one's own life represents a failure in the communication between an individual and his meaningful relations, together with an inability to cope with the stresses of life [30].

Our study relates to the onset of adolescence and the challenge of its physical and emotional changes [29]. The search for contributing factors is important, especially in Estonia, a country with a high overall suicide rate and, in particular, an elevated youth suicide rate [31].

The aim of our study was to examine schoolchildren's depressive feelings and suicidal thoughts based on gender and age in relation to (1) subjective estimation of satisfaction with relationships in the family, (2) family structure, (3) perceived ease of talking about worries to family members, and (4) family economic deprivation. The following hypotheses are tested: H1, adolescents with suicidal thoughts and depressive feelings are less satisfied with their family relationships; $\mathrm{H} 2$, adolescents with suicidal thoughts and depressive feelings find it harder to talk to their family members about their worries; $\mathrm{H} 3$, adolescents living with both birth parents have less suicidal thoughts and depressive feelings in comparison to adolescents living in non-intact families; $\mathrm{H} 4$, adolescents with suicidal thoughts and depressive feelings live in economically more deprived families.

\section{Methods}

'Health Behaviour in School-aged Children' (HBSC), a WHO Collaborative Cross-national Study, is an international research study that aims to gain new insight into, and increase our understanding of, health behaviour, health, well-being, lifestyles and social contexts amongst schoolchildren [32].

\section{Subjects}

The study was carried out amongst a random sample of Estonian schoolchildren in the context of the WHO collaborative HBSC study. Cross-sectional, school-based, anonymous questioning was conducted during the 2005/ 2006 academic year, with the standard methodology used in the HBSC study [32]. In accordance with the HBSC guidelines, a two-stage random sampling procedure was used [33]. This yielded a sample of 5,707 students. From this sample, 4,791 remained (908 students were absent on the day of the survey due to the very low outdoor temperature, 8 students refused to complete the questionnaires) and 90 questionnaires were completed incorrectly. The initial national data file was therefore composed of 4,701 
subjects. Following the data-cleansing process at the International HBSC databank in Bergen, Norway, the Estonian national data set included data on 4,477 subjects within the prescribed age limits.

Our analysis was performed only on children living in households with at least one birth parent, mother or father ( $n=4,389 ; 2,178$ boys and 2,211 girls). Schoolchildren aged $11(n=1,404 ; 683$ boys and 721 girls $), 13$ ( $n=1,434 ; 712$ boys and 722 girls) and 15 ( $n=1,544$; 779 boys and 765 girls) years old were the targets for the study. Seven subjects did not indicate their age. Mean ages were $11.8(\mathrm{SD}=0.3), 13.8(\mathrm{SD}=0.4)$ and 15.8 years $(\mathrm{SD}=0.4)$, respectively.

Data were collected by means of self-completed, standardised questionnaires in the classroom. To guarantee anonymity and confidentiality, the questionnaires were administered by a person from outside the school. The survey was approved by the Ethics Review Committee on Human Research of the University of Tartu. The study was voluntary, based on a written agreement with the representative of parents on each school council.

\section{Instrument}

The HBSC international standard questionnaire has been translated into Estonian, then (for checking translation) back-translated (blind translation) into English and compared against the original in the international coordinating centre. We chose self-reported mental health indicators (such as suicidal ideation and feeling depressed) and the following variables regarding schoolchildren's family environment, classified by gender and age group (11, 13 and 15 years):

(a) the respondents' subjective satisfaction with relationships amongst members of the family that the children were living with;

(b) perceived ease of talking about worries to family members;

(c) family structure;

(d) family economic deprivation.

Self-assessed depressiveness in schoolchildren was measured by the frequency of 'yes' and 'no' responses to the following question: 'Over the past 12 months, have you sometimes, daily for 2 weeks or more at a time, felt so sad that you have given up your usual activities?' The presence of suicidal ideation was explored variously, according to age. The 11-year-olds were asked: 'Over the past 12 months, have you ever had a serious thought that it would be better if you weren't alive any more?' The 13and 15-year-olds were asked: 'Over the past 12 months, have you ever had a serious thought of killing yourself (suicide)?'
For validation of one-item questions about suicidal thoughts and depressive feelings, subjective health complaints were measured by the HBSC symptom checklist scale from responses to the question "How often during the last 6 months have you had the following complaints (headache, stomachache, backache, feeling low, irritable, nervousness, sleeping difficulties, dizziness)?" The five options were 'almost every day', 'more than once a week', 'almost every week', 'almost every month' and 'rarely or never'. Qualitative validations of the scale have suggested that each negative complaint impacts daily life and wellbeing [28, 34]. The responses were recoded to the following categories: (1) 'yes', if the answers were 'almost every day', 'more than once a week' and 'almost every week'; (2) 'no', if the answers were 'almost every month', 'rarely or never'.

The logistic regression method was used to compare items of suicidal thoughts and depressive feelings with items of subjective health complaints. Recurrent subjective health complaints were significantly associated with higher likelihood of suicidal thoughts ('no', 'yes') and depressive feelings ('no', 'yes'). The odds ratios with $95 \%$ confidence intervals $(\mathrm{Cl})$ were statistically significant $(p<0.001)$ for all health complaints in all age groups, except backache at age 11 years $(p<0.05)$.

The odds ratio for suicidal thoughts ranged between 1.6 (back ache) and 3.8 (nervousness) at age 11 years, between 2.3 (back ache) and 4.9 (nervousness) at age 13 years, and between 2.1 (back ache) and 5.1 (feeling low) at age 15 years. The odds ratio for depressive feelings ranged between 2.1 (stomach ache) and 3.4 (feeling low) at age 11 years, between 2.0 (head ache) and 5.0 (feeling low) at age 13 years, and between 1.9 (back ache) and 4.7 (feeling low) at age 15 years.

Suicidal thoughts and depressive feelings associated significantly with subjective health complaints, which allowed us to create a suicidality-depressiveness index with the following categories: (1) presence of suicidal thoughts, with or without depressive feelings; (2) presence of depressive feelings without suicidal thoughts; and (3) without suicidal thoughts or depressive feelings, a reference group referred to in our study as 'others'.

The question showing satisfaction with mutual relationships in the family was formulated as follows: 'How satisfied are you with the relationships amongst members of your family?' Assessment ranged from 0 to 10 , with 0 denoting very poor and 10 very good relationships.

Regarding quality of communication with family members, the following question was asked: 'How easy is it for you to talk about your worries to the following people: mother, father, stepmother, stepfather, elder sister, elder brother, grandmother and grandfather?' The five options were 'very easy', 'easy' (both recoded to 'easy'), 
'difficult', 'very difficult' (both recoded to 'difficult') and 'I do not have or met such a person'. The 'family structure' section included questions about the respondent's permanent home (or the one they live in most of the time) and the other people living there (parents, step-parents, grandparents or others). The schoolchildren's families were therefore assigned to three categories according to family type: (1) birth father and birth mother in the family, (2) lone birth parent (mother or father) and (3) one birth parent and one step-parent (stepfather or stepmother).

The adolescents' material living conditions were measured in the HBSC study by Family Affluence Scale (FAS). FAS is a validated alternative evaluation of self-reported socio-economic status of adolescents for measuring family affluence and economic deprivation [35-37]. We used items from the FAS questionnaire to construct our family

Table 1 Presence of family members with whom adolescents could talk about worries

\begin{tabular}{|c|c|c|c|c|c|c|c|c|}
\hline \multirow{2}{*}{$\begin{array}{l}\text { Family } \\
\text { Members }\end{array}$} & \multicolumn{2}{|c|}{$\begin{array}{l}\text { Age } \\
11 \text { years }\end{array}$} & \multicolumn{2}{|c|}{$\begin{array}{l}\text { Age } \\
13 \text { years }\end{array}$} & \multicolumn{2}{|c|}{$\begin{array}{l}\text { Age } \\
15 \text { years }\end{array}$} & \multicolumn{2}{|l|}{ Total } \\
\hline & $N$ & $\%$ & $N$ & $\%$ & $N$ & $\%$ & $N$ & $\%$ \\
\hline Mother & 1,346 & 95.9 & 1,381 & 96.3 & 1,502 & 97.3 & 4,229 & 96.4 \\
\hline Father & 1,212 & 86.3 & 1,206 & 84.1 & 1,285 & 83.2 & 3,703 & 84.4 \\
\hline Stepmother & 178 & 12.7 & 161 & 11.2 & 140 & 9.1 & 479 & 10.9 \\
\hline Stepfather & 280 & 19.9 & 295 & 20.6 & 264 & 17.1 & 839 & 19.1 \\
\hline Grandmother & 1,272 & 90.6 & 1,242 & 86.6 & 1,334 & 86.4 & 3,848 & 87.7 \\
\hline Grandfather & 992 & 70.7 & 952 & 66.4 & 942 & 61.0 & 2,886 & 65.8 \\
\hline Elder sister & 620 & 44.2 & 644 & 44.9 & 734 & 47.5 & 1,998 & 45.5 \\
\hline Elder brother & 682 & 48.6 & 706 & 49.2 & 760 & 49.2 & 2,148 & 48.9 \\
\hline
\end{tabular}

economic deprivation index. The questions were: 'Does your family own a car, van or truck?' ('no', 'yes, one' and 'yes, two or more'). 'Do you have your own bedroom for yourself?' ('no', 'yes'). 'During the past 12 months, how many times did you travel away on holiday with your family?' ('not at all', 'once', 'twice', 'more than twice'). 'How many computers does your family own?' ('none', 'one', 'two', 'more than two'). The number of 'no' responses to these four items was counted, whereby higher score (range from 0 to 4 ) denotes deeper deprivation.

\section{Statistical procedures}

Data analyses were performed with SPSS 15.0. The impact of family factors on suicidal thoughts and depressive feelings was evaluated using multinomial logistic regression and summarised by means of odds ratios (OR) at a 95\% confidence interval (CI). The suicidality-depressiveness index described above was used as the dependent variable, and family-related factors and family economic deprivation index were used as independent variables in logistic regression analyses.

\section{Results}

Descriptive analyses

Of all the subjects $(n=4,389), 97.3 \%(n=4,271)$ lived with their birth mothers and $68.5 \%(n=3,006)$ with their birth fathers; $65.9 \%(n=2,889)$ lived with both birth parents; $18.7 \%(n=820)$ lived with a lone birth parent;

Table 2 Distribution of depressive feelings and suicidal thoughts based on age and gender

\begin{tabular}{|c|c|c|c|c|c|c|c|c|c|}
\hline & \multicolumn{3}{|c|}{ Age 11 years } & \multicolumn{3}{|c|}{ Age 13 years } & \multicolumn{3}{|c|}{ Age 15 years } \\
\hline & Boys & Girls & Total & Boys & Girls & Total & Boys & Girls & Total \\
\hline \multicolumn{10}{|c|}{ Suicidal } \\
\hline$N$ & 159 & 172 & 331 & 81 & 82 & 163 & 82 & 126 & 208 \\
\hline$\%$ & 23.6 & 24.1 & 23.8 & 11.4 & 11.4 & 11.4 & 10.6 & 16.5 & 13.5 \\
\hline \multicolumn{10}{|c|}{ Depressed } \\
\hline$N$ & 102 & 117 & 219 & 135 & 194 & 329 & 193 & 252 & 445 \\
\hline$\%$ & 15.1 & 16.4 & 15.8 & 19.1 & 27.0 & 23.1 & 24.9 & 33.1 & 29.0 \\
\hline \multicolumn{10}{|c|}{ Others } \\
\hline$N$ & 413 & 426 & 839 & 492 & 442 & 934 & 500 & 384 & 884 \\
\hline$\%$ & 61.3 & 59.6 & 60.4 & 69.5 & 61.6 & 65.5 & 64.5 & 50.4 & 57.5 \\
\hline \multicolumn{10}{|c|}{ Total } \\
\hline$N$ & 674 & 715 & 1,389 & 708 & 718 & 1,426 & 775 & 762 & 1,537 \\
\hline$\%$ & 100.0 & 100.0 & 100.0 & 100.0 & 100.0 & 100.0 & 100.0 & 100.0 & 100.0 \\
\hline
\end{tabular}

Suicidal the child has suicidal thoughts, with or without depressive feelings

Depressed the child has depressive feelings without suicidal thoughts

Others the child has neither suicidal thoughts nor depressive feelings 
and $15.5 \%(n=680)$ lived with one birth parent and one step-parent. Table 1 shows the presence of family members with whom adolescents could talk about their worries.

The distribution of depressive feelings and suicidal thoughts by age and gender is presented in Table 2 . The 30 non-responders did not answer the question on suicidal thoughts or depressive feelings. The prevalence of depressive feelings rose with age for both boys and girls ranging between 15.8 and $29.0 \%$. Suicidal ideation was more prevalent in 11-year-olds $(23.8 \%)$ compared to 13 and 15-year-olds (11.4 and 13.5\%, respectively).

Family relationships: risk and protective factors amongst boys

In our study, we examined the influence of perceived satisfaction with the quality of family relationships. Amongst the boys, those who were more satisfied with their family relationships had a lower risk of depressive feelings (odds ratio for unit increase on a ten-point scale: $\mathrm{OR}=0.8$ and $\mathrm{CI}=0.71-0.90$ at age 11 years; $\mathrm{OR}=0.8$ and $\mathrm{CI}=0.73-$ 0.89 at age 13 years; $\mathrm{OR}=0.9$ and $\mathrm{CI}=0.81-0.96$ at age 15 years). Similar results were found for suicidal thoughts in all age groups $(\mathrm{OR}=0.7$ and $\mathrm{CI}=0.62-0.76$ at age 11 years; $\mathrm{OR}=0.7$ and $\mathrm{CI}=0.62-0.78$ at age 13 years; and $\mathrm{OR}=0.7$ and $\mathrm{CI}=0.61-0.96$ at age 15 years).

Table 3 shows that boys who reported easier communication with their mother had lower risk of depressive feelings at age 11 years and lower risk of suicidal thoughts in all age groups, in comparison to boys who found it difficult to communicate with their mother. Boys who had good communication with their father had lower risk of depressive feelings and suicidal thoughts in all age groups. Ease of communication with their stepfather was negatively associated with a higher risk of depressive feelings at age 13 years (Table 3 ).

Boys who reported easy communication with an elder sister were less likely to have suicidal thoughts at ages 11 and 15 years, compared to boys who had poor communications with their elder sister. Good communication with an elder brother was negatively associated with a higher risk of suicidal thoughts at ages 11 and 15 years, and of depressive feelings at ages 13 and 15 years. Ease of communication with the grandparents was negatively associated with a higher risk of suicidal thoughts and depressive feelings at age 11 years (Table 3).

In the section on family structure, the presence of a stepparent in the family was associated with an increased risk of suicidal thoughts at ages 11 and 13 years (Table 3), in comparison to those living with both of their birth parents. Boys living in materially more deprived families were more likely to have suicidal thoughts at the age of 11 years (odds ratio for unit increase on a four-point scale: $\mathrm{OR}=1.2$ and $\mathrm{CI}=1.01-1.49$ ).

Family relationships: risk and protective factors amongst girls

Depressiveness and suicidal thoughts were less frequent in respondents who were more satisfied with their family relationships. Those girls who were more satisfied with their family relationships had a lower risk of depressive feelings at ages 13 (odds ratio for unit increase on a tenpoint scale: $\mathrm{OR}=0.8$ and $\mathrm{CI}=0.76-0.91$ ) and 15 years $(\mathrm{OR}=0.9$ and $\mathrm{CI}=0.84-0.99)$, and of suicidal thoughts in all age groups $(\mathrm{OR}=0.8$ and $\mathrm{CI}=0.69-0.83$ at age 11 ; $\mathrm{OR}=0.7$ and $\mathrm{CI}=0.61-0.76$ at age 13 ; and $\mathrm{OR}=0.7$ and $\mathrm{CI}=0.63-0.76$ at age 15 years).

Table 4 shows that in girls, ease of communication with their mother was associated with a lower risk of depressive feelings at age 13 years and reduced risk of suicidal thoughts in all age groups. Ease of communication with the father was negatively associated with a higher risk of depressive feelings at ages 13 and 15 years and of suicidal thoughts in all age groups. Good communication with the stepmother was negatively associated with a higher risk of depressive feelings at age 15 years. Good communication with the stepfather was negatively associated with higher risk of suicidal thoughts at age 11 years (Table 4).

Girls who could communicate easily with their elder sister had a lower risk of suicidal thoughts at age 11 years, compared to girls who had poor communications with their elder sister. Good communication with an elder brother was negatively associated with a higher risk of suicidal thoughts at age 15 years. Ease of communication with the grandparents was negatively associated with a higher risk of suicidal thoughts at ages 11 and 15 years (Table 4).

In the section on family structure, the presence of a stepparent in the family was associated with an increased risk of suicidal thoughts in all age groups and for depressive feelings at age 13 years. Fifteen-year-olds who lived with a single parent were more likely to have suicidal thoughts (Table 4) than those who lived with two birth parents.

Girls living in materially more deprived families were more likely to have suicidal thoughts at ages 11 (odds ratio for unit increase on four-point scale: $\mathrm{OR}=1.2$ and $\mathrm{CI}=1.02-1.46)$ and 15 years $(\mathrm{OR}=1.5$ and $\mathrm{CI}=1.20$ 1.76).

Multinomial logistic regression model

A multinomial logistic regression model was used to examine the relationship between family structure variables and suicidal thoughts and depressive feelings. Table 5 shows the logistic regression model by age groups 
Table 3 Odds ratios for suicidal thoughts and depressive feelings in relation to family-related factors (ease of talking about worries and family structure variables), logistic regression for boys, based on age group

\begin{tabular}{|c|c|c|c|c|c|c|c|}
\hline \multirow[t]{2}{*}{ Family member } & & \multicolumn{2}{|c|}{ Age 11 years } & \multicolumn{2}{|c|}{ Age 13 years } & \multicolumn{2}{|c|}{ Age 15 years } \\
\hline & & OR & $95 \% \mathrm{CI}$ & OR & $95 \% \mathrm{CI}$ & OR & $95 \% \mathrm{CI}$ \\
\hline \multicolumn{8}{|c|}{ Suicidal versus others } \\
\hline \multirow[t]{2}{*}{ Mother } & Easy & $0.3 * * *$ & $0.17-0.54$ & $0.3 * * *$ & $0.18-0.63$ & $0.1 * * *$ & $0.08-0.23$ \\
\hline & Difficult & 1.0 & & 1.0 & & 1.0 & \\
\hline \multirow[t]{2}{*}{ Father } & Easy & $0.5 * * *$ & $0.29-0.73$ & $0.3 * * *$ & $0.17-0.53$ & $0.4 * * *$ & $0.21-0.59$ \\
\hline & Difficult & 1.0 & & 1.0 & & 1.0 & \\
\hline \multirow[t]{2}{*}{ Stepmother } & Easy & 0.8 & $0.29-2.29$ & 0.6 & $0.17-2.26$ & 2.1 & $0.41-10.63$ \\
\hline & Difficult & 1.0 & & 1.0 & & 1.0 & \\
\hline \multirow[t]{2}{*}{ Stepfather } & Easy & 0.9 & $0.41-2.05$ & 1.2 & $0.48-3.18$ & 0.4 & $0.09-1.48$ \\
\hline & Difficult & 1.0 & & 1.0 & & 1.0 & \\
\hline \multirow[t]{2}{*}{ Elder sister } & Easy & $0.4 * *$ & $0.22-0.72$ & 0.7 & $0.32-1.32$ & $0.3 * * *$ & $0.16-0.62$ \\
\hline & Difficult & 1.0 & & 1.0 & & 1.0 & \\
\hline \multirow[t]{2}{*}{ Elder brother } & Easy & $0.3 * * *$ & $0.15-0.46$ & 1.5 & $0.60-3.79$ & $0.4^{*}$ & $0.21-0.87$ \\
\hline & Difficult & 1.0 & & 1.0 & & 1.0 & \\
\hline \multirow[t]{2}{*}{ Grandmother } & Easy & $0.3 * * *$ & $0.19-0.49$ & 0.9 & $0.50-1.63$ & 0.6 & $0.38-1.06$ \\
\hline & Difficult & 1.0 & & 1.0 & & 1.0 & \\
\hline \multirow[t]{2}{*}{ Grandfather } & Easy & $0.3 * * *$ & $0.20-0.54$ & 0.8 & $0.41-1.41$ & 0.7 & $0.37-1.19$ \\
\hline & Difficult & 1.0 & & 1.0 & & 1.0 & \\
\hline \multicolumn{2}{|c|}{ Lone birth parent } & 0.9 & $0.52-1.58$ & 1.3 & $0.66-2.51$ & 0.9 & $0.52-1.72$ \\
\hline \multicolumn{2}{|c|}{1 birth parent, 1 step-parent } & $1.9 * *$ & $1.17-3.09$ & $3.4 * * *$ & $1.93-5.96$ & 0.8 & $0.40-1.79$ \\
\hline \multicolumn{2}{|c|}{ Both birth parents } & 1.0 & & 1.0 & & 1.0 & \\
\hline \multicolumn{8}{|c|}{ Depressed versus others } \\
\hline \multirow[t]{2}{*}{ Mother } & Easy & $0.3 * * *$ & $0.16-0.58$ & 0.6 & $0.33-1.03$ & 0.7 & $0.45-1.15$ \\
\hline & Difficult & 1.0 & & 1.0 & & 1.0 & \\
\hline \multirow[t]{2}{*}{ Father } & Easy & $0.4 * * *$ & $0.24-0.69$ & $0.5 * *$ & $0.31-0.78$ & $0.5 * * *$ & $0.30-0.66$ \\
\hline & Difficult & 1.0 & & 1.0 & & 1.0 & \\
\hline \multirow[t]{2}{*}{ Stepmother } & Easy & 2.6 & $0.67-9.88$ & 1.0 & $0.25-3.83$ & 1.3 & $0.43-3.89$ \\
\hline & Difficult & 1.0 & & 1.0 & & 1.0 & \\
\hline \multirow[t]{2}{*}{ Stepfather } & Easy & 3.1 & $0.77-12.35$ & $0.4^{*}$ & $0.13-0.93$ & 0.7 & $0.31-1.54$ \\
\hline & Difficult & 1.0 & & 1.0 & & 1.0 & \\
\hline \multirow[t]{2}{*}{ Elder sister } & Easy & 0.5 & $0.23-1.10$ & 0.8 & $0.41-1.45$ & 0.9 & $0.49-1.58$ \\
\hline & Difficult & 1.0 & & 1.0 & & 1.0 & \\
\hline \multirow[t]{2}{*}{ Elder brother } & Easy & 0.5 & $0.22-1.08$ & $0.6^{*}$ & $0.31-0.98$ & $0.5^{*}$ & $0.32-0.86$ \\
\hline & Difficult & 1.0 & & 1.0 & & 1.0 & \\
\hline \multirow[t]{2}{*}{ Grandmother } & Easy & 0.6 & $0.33-1.09$ & 0.9 & $0.57-1.41$ & 0.8 & $0.56-1.19$ \\
\hline & Difficult & 1.0 & & 1.0 & & 1.0 & \\
\hline Grandfather & Easy & $0.5 * *$ & $0.25-0.82$ & 1.0 & $0.60-1.55$ & 0.9 & $0.56-1.31$ \\
\hline & Difficult & 1.0 & & 1.0 & & 1.0 & \\
\hline Lone birth par & & 1.3 & $0.75-2.36$ & 1.2 & $0.71-1.92$ & 1.0 & $0.65-1.53$ \\
\hline 1 birth parent, & arent & 0.9 & $0.45-1.82$ & 0.9 & $0.46-1.61$ & 1.1 & $0.69-1.85$ \\
\hline Both birth par & & 1.0 & & 1.0 & & 1.0 & \\
\hline
\end{tabular}

OR odds ratio, 95\% CI confidence interval at 95\% confidence level

Suicidal the child has suicidal thoughts, with or without depressive feelings

Depressed the child has depressive feelings without suicidal thoughts

Others children with neither suicidal thoughts nor depressive feelings

* $P<0.05$, ** $P<0.01$, *** $P<0.001$ 
Table 4 Odds ratios for suicidal thoughts and depressive feelings in relation to family-related factors (ease of talking about worries and family structure variables), logistic regression for girls, based on age group

\begin{tabular}{|c|c|c|c|c|c|c|c|}
\hline \multirow[t]{2}{*}{ Family member } & & \multicolumn{2}{|c|}{ Age 11 years } & \multicolumn{2}{|c|}{ Age 13 years } & \multicolumn{2}{|c|}{ Age 15 years } \\
\hline & & OR & $95 \% \mathrm{CI}$ & OR & $95 \% \mathrm{CI}$ & OR & $95 \% \mathrm{CI}$ \\
\hline \multicolumn{8}{|c|}{ Suicidal versus others } \\
\hline \multirow[t]{2}{*}{ Mother } & Easy & $0.3 * * *$ & $0.13-0.49$ & $0.3 * * *$ & $0.16-0.59$ & $0.2 * * *$ & $0.14-0.38$ \\
\hline & Difficult & 1.0 & & 1.0 & & 1.0 & \\
\hline \multirow[t]{2}{*}{ Father } & Easy & $0.5^{* * *}$ & $0.31-0.73$ & $0.4 * * *$ & $0.21-0.63$ & $0.4 * * *$ & $0.25-0.65$ \\
\hline & Difficult & 1.0 & & 1.0 & & 1.0 & \\
\hline \multirow[t]{2}{*}{ Stepmother } & Easy & 1.2 & $0.48-3.17$ & 2.0 & $0.60-6.43$ & 0.3 & $0.09-1.17$ \\
\hline & Difficult & 1.0 & & 1.0 & & 1.0 & \\
\hline \multirow[t]{2}{*}{ Stepfather } & Easy & $0.5^{*}$ & $0.22-0.95$ & 0.4 & $0.15-1.29$ & 1.7 & $1.70-4.15$ \\
\hline & Difficult & 1.0 & & 1.0 & & 1.0 & \\
\hline \multirow[t]{2}{*}{ Elder sister } & Easy & $0.4^{* *}$ & $0.18-0.69$ & 0.6 & $0.22-1.33$ & 1.1 & $0.48-2.63$ \\
\hline & Difficult & 1.0 & & 1.0 & & 1.0 & \\
\hline \multirow[t]{2}{*}{ Elder brother } & Easy & 0.6 & $0.37-1.02$ & 0.6 & $0.30-1.28$ & $0.5 *$ & $0.29-0.99$ \\
\hline & Difficult & 1.0 & & 1.0 & & 1.0 & \\
\hline \multirow[t]{2}{*}{ Grandmother } & Easy & $0.5^{* *}$ & $0.31-0.78$ & 0.6 & $0.35-1.01$ & $0.4 * * *$ & $0.27-0.66$ \\
\hline & Difficult & 1.0 & & 1.0 & & 1.0 & \\
\hline \multirow[t]{2}{*}{ Grandfather } & Easy & $0.4 * * *$ & $0.28-0.67$ & 0.7 & $0.37-1.23$ & $0.5 *$ & $0.28-0.93$ \\
\hline & Difficult & 1.0 & & 1.0 & & 1.0 & \\
\hline \multicolumn{2}{|c|}{ Lone birth parent } & 1.3 & $0.84-2.06$ & 1.1 & $0.59-2.17$ & $2.3 * * *$ & $1.43-3.76$ \\
\hline \multicolumn{2}{|c|}{1 birth parent, 1 step-parent } & $1.6^{*}$ & $1.01-2.66$ & $2.1 * *$ & $1.19-3.69$ & $1.8^{*}$ & $1.03-2.99$ \\
\hline \multicolumn{2}{|c|}{ Both birth parents } & 1.0 & & 1.0 & & 1.0 & \\
\hline \multicolumn{8}{|c|}{ Depressed versus others } \\
\hline \multirow[t]{2}{*}{ Mother } & Easy & 1.1 & $0.37-3.40$ & $0.5^{* *}$ & $0.27-0.77$ & 0.7 & $0.46-1.18$ \\
\hline & Difficult & 1.0 & & 1.0 & & 1.0 & \\
\hline \multirow[t]{2}{*}{ Father } & Easy & 0.7 & $0.39-1.08$ & $0.6^{* *}$ & $0.41-0.87$ & $0.6^{*}$ & $0.45-0.91$ \\
\hline & Difficult & 1.0 & & 1.0 & & 1.0 & \\
\hline \multirow[t]{2}{*}{ Stepmother } & Easy & 3.0 & $0.76-11.40$ & 0.7 & $0.26-1.88$ & $0.2 *$ & $0.03-0.71$ \\
\hline & Difficult & 1.0 & & 1.0 & & 1.0 & \\
\hline \multirow[t]{2}{*}{ Stepfather } & Easy & 0.6 & $0.25-1.47$ & 1.1 & $0.57-2.32$ & 1.0 & $0.48-2.21$ \\
\hline & Difficult & 1.0 & & 1.0 & & 1.0 & \\
\hline \multirow[t]{2}{*}{ Elder sister } & Easy & 2.8 & $0.63-12.31$ & 0.9 & $0.46-1.69$ & 0.6 & $0.31-1.13$ \\
\hline & Difficult & 1.0 & & 1.0 & & 1.0 & \\
\hline \multirow[t]{2}{*}{ Elder brother } & Easy & 1.0 & $0.50-1.80$ & 1.3 & $0.73-2.15$ & 0.8 & $0.49-1.31$ \\
\hline & Difficult & 1.0 & & 1.0 & & 1.0 & \\
\hline \multirow[t]{2}{*}{ Grandmother } & Easy & 1.0 & $0.52-1.73$ & 0.9 & $0.60-1.13$ & 0.8 & $0.57-1.17$ \\
\hline & Difficult & 1.0 & & 1.0 & & 1.0 & \\
\hline Grandfather & Easy & 0.7 & $0.39-1.09$ & 0.9 & $0.64-1.47$ & 0.7 & $0.47-1.13$ \\
\hline & Difficult & 1.0 & & 1.0 & & 1.0 & \\
\hline Lone birth par & & 1.1 & $0.67-1.93$ & 1.4 & $0.90-2.16$ & 1.2 & $082-1.87$ \\
\hline 1 birth parent, & rent & 1.5 & $0.83-2.56$ & $1.8^{* *}$ & $1.14-2.71$ & 1.1 & $070-1.68$ \\
\hline Both birth par & & 1.0 & & 1.0 & & 1.0 & \\
\hline
\end{tabular}

OR odds ratio, $95 \%$ CI confidence interval at $95 \%$ confidence level

Suicidal the child has suicidal thoughts, with or without depressive feelings

Depressed the child has depressive feelings without suicidal thoughts

Others children with neither suicidal thoughts nor depressive feeling

* $P<0.05$, ** $P<0.01$, *** $P<0.001$ 
Table 5 Predictors of suicidal thoughts and depressive feelings in the context of family-related factors (ease of talking about worries with mother or father, family structure variables and family economic deprivation) and gender, multinomial logistic regression model based on age group

\begin{tabular}{|c|c|c|c|c|c|c|c|}
\hline \multirow{2}{*}{\multicolumn{2}{|c|}{ Family-related variables and gender }} & \multicolumn{2}{|c|}{ Age 11 years } & \multicolumn{2}{|c|}{ Age 13 years } & \multicolumn{2}{|c|}{ Age 15 years } \\
\hline & & OR & $95 \% \mathrm{CI}$ & OR & $95 \% \mathrm{CI}$ & OR & $95 \% \mathrm{CI}$ \\
\hline \multicolumn{8}{|c|}{ Suicidal versus others } \\
\hline \multicolumn{2}{|c|}{ Family economic deprivation } & 1.1 & $0.97-1.30$ & 1.1 & $0.89-1.30$ & $1.3 * *$ & $1.08-1.51$ \\
\hline \multirow[t]{2}{*}{ Gender } & Boys & 1.0 & $0.73-1.25$ & 1.0 & $0.70-1.44$ & $0.5 * * *$ & $0.39-0.76$ \\
\hline & Girls & 1.0 & & 1.0 & & 1.0 & \\
\hline \multirow[t]{3}{*}{ Mother } & Easy & $0.3 * * *$ & $0.20-0.52$ & $0.4 * * *$ & $0.28-0.71$ & $0.2 * * *$ & $0.15-0.31$ \\
\hline & Don't have mother & $0.3^{*}$ & $0.10-0.82$ & 2.3 & $0.87-5.95$ & $0.2 * *$ & $0.05-0.66$ \\
\hline & Difficult & 1.0 & & 1.0 & & 1.0 & \\
\hline \multirow[t]{3}{*}{ Father } & Easy & $0.6 * *$ & $0.43-0.84$ & $0.4 * * *$ & $0.26-0.58$ & $0.5^{* * *}$ & $0.36-0.76$ \\
\hline & Don't have father & 0.8 & $0.46-1.32$ & 0.6 & $0.34-1.10$ & 0.8 & $0.45-1.30$ \\
\hline & Difficult & 1.0 & & 1.0 & & 1.0 & \\
\hline Family & Lone birth parent & 1.0 & $0.63-1.47$ & 1.1 & $0.61-1.82$ & 1.1 & $0.71-1.79$ \\
\hline \multirow[t]{2}{*}{ Structure } & 1 birth parent, 1 step-parent & $1.7 * *$ & $1.13-2.51$ & $2.2 * * *$ & $1.37-3.55$ & 1.2 & $0.75-2.02$ \\
\hline & Both birth parents & 1.0 & & 1.0 & & 1.0 & \\
\hline \multicolumn{8}{|c|}{ Depressed versus others } \\
\hline \multicolumn{2}{|c|}{ Family economic 1 deprivation } & 1.0 & $0.86-1.21$ & 1.0 & $0.84-1.11$ & 1.0 & $0.84-1.10$ \\
\hline \multirow[t]{2}{*}{ Gender } & Boys & 0.9 & $0.68-1.26$ & $0.7 * *$ & $0.52-0.89$ & $0.6 * * *$ & $0.50-0.80$ \\
\hline & Girls & 1.0 & & 1.0 & & 1.0 & \\
\hline \multirow[t]{3}{*}{ Mother } & Easy & $0.5^{*}$ & $0.29-0.89$ & $0.6^{* *}$ & $0.38-0.84$ & 0.8 & $0.56-1.11$ \\
\hline & Don't have mother & 0.3 & $0.08-1.16$ & 0.4 & $0.10-1.37$ & 0.6 & $0.23-1.54$ \\
\hline & Difficult & 1.0 & & 1.0 & & 1.0 & \\
\hline \multirow[t]{3}{*}{ Father } & Easy & $0.6 * *$ & $0.41-0.87$ & $0.6^{* *}$ & $0.46-0.85$ & $0.6^{* * *}$ & $0.43-0.73$ \\
\hline & Don't have father & 0.7 & $0.40-1.37$ & 0.7 & $0.41-1.09$ & 0.7 & $0.48-1.10$ \\
\hline & Difficult & 1.0 & & 1.0 & & 1.0 & \\
\hline Family & Lone birth parent & 1.2 & $0.74-1.86$ & 1.2 & $0.83-1.83$ & 1.1 & $0.76-1.55$ \\
\hline \multirow[t]{2}{*}{ Structure } & 1 birth parent, 1 step-parent & 1.2 & $0.73-1.94$ & 1.2 & $0.84-1.86$ & 1.1 & $0.72-1.54$ \\
\hline & Both birth parents & 1.0 & & 1.0 & & 1.0 & \\
\hline
\end{tabular}

OR odds ratio, $95 \% \mathrm{CI}$ confidence interval at $95 \%$ confidence level

Suicidal the child has suicidal thoughts, with or without depressive feelings

Depressed the child has depressive feelings without suicidal thoughts

Others children with neither suicidal thoughts nor depressive feelings

$* P<0.05, * * P<0.01, * * * P<0.001$

to predict suicidal thoughts and depressive feelings in the context of family-related factors (ease of talking about worries separately with their mother or father, and family structure variables) and gender. The suicidality-depressive index was the dependent variable and the three familyrelated factors were the independent variables. A variable characterising economic deprivation in the family was included in the regression analysis to statistically control it. Adolescents with depressive feelings and suicidal thoughts were compared to adolescents with neither depressive feelings nor suicidal thoughts.

Gender differences emerged for depressive feelings at ages 13 and 15 years, and for suicidal thoughts at age 15 years. Girls aged 13 and 15 years had a higher risk of depressive feelings than boys of the same age, and 15-yearold girls had higher risk of suicidal thoughts when compared to 15 -year-old boys.

Adolescents who reported easy communication with the mother were less likely to have suicidal thoughts in all age groups and depressive feelings at ages 11 and 13 years, compared to adolescents who had poor communications with their mother. Adolescents aged 11 and 15 years who reported poor communication with their birth mother had an increased risk of suicidal thoughts, when compared to those adolescents who did not have a mother in the family. Good communication with the father was negatively associated with a higher risk of depressive feelings and of suicidal thoughts in all age groups. 
The presence of a step-parent in the family was associated with an increased risk of suicidal thoughts at ages 11 and 13 years, in comparison to those living with both of their birth parents. Economic deprivation of the adolescent's family was associated with an increased risk of suicidal thoughts at age 15 years (Table 5).

\section{Discussion}

The WHO Collaborative Cross-national Study 'Health Behaviour in School-aged Children' (HBSC) was used as an instrument to analyse the risk for suicidal ideation and depressive feelings in the family context, in a non-clinical sample of Estonian schoolchildren. Family-related variables included family structure, subjective evaluation of satisfaction with the relationships amongst family members and perceived ease of talking about worries to different family members.

\section{Suicidal thoughts and depressive feelings}

In total, approximately $40 \%$ of schoolchildren reported suicidal ideation and/or depressive feelings. Although this is not a clinical diagnosis but a self-report based on a single question, the finding suggests that a surprisingly high proportion of schoolchildren in Estonia lack psychological well-being in their everyday life.

The prevalence of suicidal thoughts and depressive feelings varied amongst the age groups. The proportion of respondents experiencing depressive feelings rose with age for both boys and girls. In contrast, the highest proportion of respondents reporting suicidal ideation, almost a quarter of the schoolchildren, was found amongst the 11-year-olds, while the proportions of 13- and 15-year-olds with suicidal thoughts were considerably lower. However, the reason for the high rate of suicidal ideation in the youngest group is probably a technical issue, rather than being 'meaningful', since the questions for the assessment of this group's suicidal ideation were worded differently. The 11-year-olds were asked whether they had any serious thoughts that it might be better if they were not alive any more, while the 13- and 15-year-olds were asked directly whether they had ever had any serious thought about killing themselves. The wording of the question the 11-year-olds were asked may reflect on aspects of their relationships, rather than on a suicidal process [3].

Gender differences for depressive feelings started to emerge from the age of 13 years and for suicidal ideation from 15 years, with girls having higher risk in both. This pattern of gender divergence may have both biological and sociological explanations. Biologically, the younger children did not develop to the stage where mental health risk factors were differentiated; sociologically, the social and family status of the younger age group was not genderspecific [38-40]. Additionally, the higher rate of depression in girls compared with boys after the onset of puberty may be caused by different coping styles or hormonal changes during puberty [17].

Almost half of the 15-year-old girls reported suicidal ideation and/or depressive feelings. This was a significantly higher proportion than amongst the boys. As a previous study has shown, girls tend to manifest internally focused characteristics of depressive symptoms, while boys tend to show more behavioural components [38]. In most countries, suicide rates are considerably higher amongst boys than girls [31].

\section{Family structure}

In Estonia, the proportion of families with both birth parents is decreasing, while the proportion of families with single parents and step-parents is rising [29]. Given both this fact and the high prevalence of suicidal ideation and depressive feelings in Estonian schoolchildren, the idea of evaluating associations between children's mental health status and family structure arose.

One tendency that emerged was that living in a singleparent family did not increase the likelihood of boys having suicidal thoughts and/or depressive feelings. The same applied to girls aged 11 and 13 years. The only significant association was found in 15-year-old girls, who had a higher probability of experiencing suicidal thoughts if they had only one parent in the family. From the psychodynamic perspective, one possible implication of the features of a suicidal child's family system may be a symbiotic parent-child relationship: because of particularly intense and rigid interaction with (usually) the mother, the child may not be able to develop autonomous functioning successfully [19]. This could be one possible explanation for the exceptional finding regarding 15 -year-old girls' suicidal ideation, although the authors admit that this is sheer speculation and the results of the current study provide no direct indications of such conclusions.

Having a step-parent in the family, compared with living with both birth parents, meant an elevated risk for suicidal thoughts at ages 11 and 13 years. The association between having a step-parent in the family and the adolescent's depressive feelings was less clear. Unfortunately, the current study does not provide any information about the timing of the step-parent's entry into the family. However, one possible explanation for the increased risk of child's suicidal ideation may be that parental attention must now be divided between the child and another family member, the new partner, who may be perceived by the child as an invader. Dilution and deterioration of parental resources in 
the family are not conducive to children's mental health and may be important in explaining the effects on the children's emotional and behavioural outcomes [1].

Garniefski and Diekstra have reported an association with an elevated rate of attempted suicide for boys living with a step-parent [41]. In our study, the presence of a stepparent in the family structure was found to increase the probability of adolescent reporting suicidal thoughts. However, good communication quality between the adolescent and the step-parent reduced the depressive feelings in 15-year-old girls with their stepmother and in 13-yearold boys with their stepfather.

Family relationships and communication

Relationships between the members of a family are reflected in an adolescents' mental health [20, 22, 42, 43]. In our study, perceived satisfaction with relationships in the family markedly reduced the likelihood of reporting suicidal ideation and depressive feelings. The quality of the adolescent's family relationships, as part of their psychosocial environment, has an impact not only on their current mental health status, but also on their prospects of developing mental health problems, such as major depression, in later life [44]. However, there have also been research findings showing that depressed children perceive their family environment to be relatively more distressed [45].

Good communication with the mother or father reduces the risk of suicidal ideation in both genders and in all age groups. The same pattern emerges for depressive feelings with one exception only: in 15-year-olds, the ease of talking about worries with their mother has no effect. The results of the present study highlight the importance of close and trusting parent-adolescent relationships. Evidently, if schoolchildren can talk about their worries with their parents, they are less likely to report both suicidal ideation and depressive feelings.

The multinomial regression model revealed that the adolescents who had difficulties in communicating with their mother had a higher probability for suicidal thoughts than those who did not have their mother. Further to the children's social context, we also found relationships with the children's material context. Economic deprivation in the family may contribute to an increased risk for suicidal thoughts at the age of 15 years. Ease of communication with the mother or father is independently associated with decreased risk of suicidal ideation, and living with a stepparent independently is associated with increased risk for suicidal ideation even after adjusting for the presence of economic deprivation variables.

A previous study showed that children from a higher socio-economic background found it easier to communicate with their father, but there were no differences in the case of the mother [15]. Low familial affluence was associated with poor general health perception and multiple recurrent subjective health complaints [46]. In a longitudinal study, the childhood profile of those at greatest risk of suicidal behaviour included being raised in socio-economic adversity, marital disruption and poor parent-child attachment [9].

Adams et al. [47] indicated that perceived family functioning and mother-adolescent or parent-adolescent dyadic relationships were significantly correlated with levels of depression, hopelessness and self-esteem. Suicidal psychiatric inpatients and suicidal high school students showed no difference in their perceptions of family functioning and mother-adolescent relationships. Both groups reported more distress and family dysfunction than the non-suicidal high school students.

Our study pinpointed the extended family as one possible protective factor against suicidal thoughts and brought out grandparents as significant others, especially for schoolchildren of younger ages. Grandparents had less influence on depressive feelings. Apparently, there are benefits in cross-generational family relationships. One previous study has singled out grandparents as a special resource for children in stepfamilies [48].

Family resources are often seen in terms of relationships with adults, but sibling structure, with the emphasis on the impact of group configuration on social interaction, is another family resource. Our study brought out the possible influence of good communication with an elder sister or elder brother on the child's mental health. In line with previous findings, our study supports the importance of group configuration for siblings' social interaction [49] and of protection against the onset of depression [24].

The boundaries between suicidal thoughts and suicide attempts are not distinct, but fluid, and the outcome is influenced by risk and protective factors [3]. Wasserman indicated that suicidality could be regarded not as an illness, but as an act stemming from the interplay between cognitive, affective and communication factors. The process of engaging in dialogue requires the conversion of abstract thoughts into concrete language. This process may help suicidal people make better sense of their elusive experiences. Moreover, dialogue enables the adolescent to see the issue from another perspective, which can correct previously maladaptive perspectives. To prevent suicidal people from resorting to suicide, it is important to take their every reference to suicide seriously [3].

\section{Conclusion}

Adolescents who are more satisfied with their family relationships have less depressive feelings and suicidal thoughts. 
The ease of talking about their worries with parents has a protective effect, but grandparents and siblings may also be considered a valuable protective resource. Family structure can have an important role and adolescents who live with both birth parents have fewer depressive feelings and suicidal thoughts. Adolescents who live with a stepparent have more suicidal thoughts than those in single-parent families. Family economic deprivation is a risk factor for suicidal thoughts, but the aforementioned associations between family-related variables and suicidal thoughts remained significant even after adjusting for family economic deprivation. Familial resources should be addressed as protective factors when implementing mental health promotion and suicide prevention programmes.

\section{Limitations}

The proportion of schoolchildren not included in our study was $24 \%$ of the total sample: for technical reasons (incompleteness of the form), because some were absent from school (mainly because of the low temperature) and other pupils declined to fill in the questionnaire.

The limitation with respect to the methodology was a difference in the wording of the question about suicidality presented to 11-year-olds and to the older age groups (13 and 15 years) that limit direct comparisons between age groups.

The research was limited to schoolchildren's selfreported perceived quality of relationships and ease of communication with family members, and these variables reflect only the emotional side of relationships. As previous studies have indicated, family circumstances afford only a limited understanding of adolescent risk behaviour [50]. There are other environmental-related factors, such as vulnerability through parental psychopathology and substance use, presence of major life events, medical illness, peer relationships, etc., which probably have a major impact on schoolchildren's mental health. Further research is needed to explore the consequences of combinations of several dysfunctional variables.

The HBSC study had a cross-sectional design, which made it impossible to infer causal relationship between cognitions and depressive mood/suicidal ideation. Therefore, the interpretation of these findings needs to be considered in the context of several limitations. For example, dysfunctional family relationships can lead to depressiveness and suicidal ideation, or pre-existing depression can distort the child's perception of his family relationships. Longitudinal studies are needed to draw conclusions about causality.

Acknowledgments This study was made possible within the framework of the Estonian Science Foundation's Project No. 7132 and Doctoral School of Estonian Centre of Behavioural and Health
Sciences. HBSC is an international study carried out in collaboration with WHO/EURO. The International Coordinator of the HBSC 2005/ 06 survey was Candace Currie and the data bank manager was Oddrun Samdal. Thanks are due to Clare James for her thorough linguistic and stylistic revision of the manuscript.

\section{References}

1. Mann JJ, Waternaux C, Haas GL, Malone KM (1999) Toward a clinical model of suicidal behavior in psychiatric patients. Am J Psychiatry 156:181-189

2. Paykel ES (1974) Suicidal feelings in the general population: a prevalence study. Br J Psychiatry 124:460-469

3. Wasserman D (2001) A stress-vulnerability model and the development of the suicidal process. In: Wasserman D (ed) Suicide_-an unnecessary death. Martin Dunitz Ltd, London, pp $13-28$

4. Kaltiala-Heino R, Rimpela M, Marttunen M, Rimpela A, Rantanen P (1999) Bullying, depression, and suicidal ideation in Finnish adolescents: school survey. Br Med J 319:348-351

5. Larsson B, Melin L (1992) Prevalence and short-term stability of depressive symptoms in schoolchildren. Acta Psychiatr Scand $85: 17-22$

6. Saluja G, Iachan R, Scheidt PC, Overpeck MD, Sun W, Giedd JN (2004) Prevalence of and risk factors for depressive symptoms among young adolescents. Arch Pediatr Adolesc Med 158:760-765

7. Viñas F, Canals J, Gras ME, Ros C, Domènech-Llaberia E (2002) Psychological and family factors associated with suicidal ideation in pre-adolescents. Span J Psychol 5:20-28

8. Apter A (2003) Biological factors influencing suicidal behavior in adolescents. In: King RA, Apter A (eds) Suicide in children and adolescents. University Press, Cambridge, pp 118-149

9. Fergusson DM, Woodward LJ, Horwood LJ (2000) Risk factors and life processes associated with the onset of suicidal behaviour during adolescence and early adulthood. Psychol Med 30:23-39

10. King CA, Merchant CR (2008) Social and interpersonal factors relating to adolescent suicidality: a review of the literature. Arch Suicide Res 12:181-196

11. Koplin B, Agathen J (2002) Suicidality in children and adolescents: a review. Curr Opin Pediatr 14:713-717

12. Lau JYF, Rijsdijk F, Gregory AM, McGuffin P, Eley TC (2007) Pathways to childhood depressive symptoms: the role of social, cognitive, and genetic risk factors. Develop Psychol 43:14021414

13. Mortensen PB, Agerbo E, Erikson T, Qin P, Westergaard-Nielsen N (2000) Psychiatric illness and risk factors for suicide in Denmark. Lancet 355:9-12

14. Statham DJ, Heath AC, Madden PA, Bucholz KK, Bierut L, Dinwiddie SH, Slutske WS, Dunne MP, Martin NG (1998) Suicidal behaviour: an epidemiological and genetic study. Psychol Med 28:839-855

15. Zambon A, Lemma P, Borraccino A, Dalmasso P, Cavallo F (2006) Socio-economic position and adolescents' health in Italy: the role of the quality of social relations. Eur J Public Health $16: 627-632$

16. Bhatia SK, Bhatia SC (2007) Childhood and adolescent depression. Am Fam Physician 75:73-80

17. Zalsman G, Brent DA, Weersing VR (2006) Depressive disorders in childhood and adolescence: an overview: epidemiology, clinical manifestation and risk factors. Child Adolesc Psychiatr Clin N Am 15:827-841

18. Wasserman D (2006) Depression in childhood and adolescence. Wasserman D (ed) Depression: the facts. Oxford University Press, Oxford, pp 43-61 
19. Pfeffer CR (1981) The family system of suicidal children. Am J Psychother 35:330-341

20. Garber J, Little S, Hilsman R, Weaver KR (1998) Family predictors of suicidal symptoms in young adolescents. J Adolesc 21:445-457

21. Summerville MB, Kaslow NJ, Abbate MF, Cronan S (1994) Psychopathology, family functioning, and cognitive style in urban adolescents with suicide attempts. J Abnorm Child Psychol 22:221-235

22. Morano CD, Cisler RA, Lemerond J (1993) Risk factors for adolescent suicidal behavior: loss, insufficient familial support, and hopelessness. Adolescence 28:851-865

23. Cauce AM, Mason C, Gonzales N, Hiraga Y, Liu G (1996) Social support during adolescence: methodological and theoretical considerations. In: Hurrelmann K, Hamilton SF (eds) Social problems and social contexts in adolescence: perspectives across boundaries. Aldine de Gryter, New York, pp 131-152

24. McFarlane AH, Bellissimo A, Norman GR, Lange P (1994) Adolescent depression in a school-based community sample: preliminary findings on contributing social factors. J Youth Adolesc 23:601-620

25. Ram B, Hou F (2003) Changes in family structure and child outcomes: roles of economic and familial resources. Policy Stud J 31:309-330

26. Luoma I, Puura K, Tamminen T, Kaukonen P, Piha J, Rasanen E, Kumpulainen K, Moilanen I, Koivisto AM, Almqvist F (1999) Emotional and behavioural symptoms in 8-9-year-old children in relation to family structure. Eur Child Adolesc Psychiatry 8(Suppl 4):29-40

27. Hirsch J, Ellis JB (1995) Family support and other social factors precipitating suicidal ideation. Int J Soc Psychiatry 41:26-30

28. Torsheim T, Ravens-Sieberer U, Hetland J, Välimaa R, Danielson M, Overpeck M (2006) Cross-national variation of gender differences in adolescent subjective health in Europe and North America. Soc Sci Med 62:815-827

29. Currie C, Gabhainn SN, Godeau E, Roberts C, Smith R, Currie D, Picket W, Richter M, Morgan A, Barnekow V (2008) Inequalities in young people's health: HBSC international report from the 2005/2006 Survey. WHO Regional Office for Europe, Copenhagen, 2008 (Health Policy Child and Adolesc No. 5)

30. Sabbath JC (1969) The suicidal adolescent: the expendable child. In: Maltsberger JT, Goldblatt MJ (eds) Essential papers on suicide. New York University Press, New York, pp 185-199

31. Varnik A, Kolves K, Allik J, Arensman E, Aromaa E, van Audenhove C, Bouleau JH, van der Feltz-Cornelis CM, Giupponi G, Gusmao R, Kopp M, Marusic A, Maxwell M, Oskarsson H, Palmer A, Pull C, Realo A, Reisch T, Schmidtke A, Sola VP, Wittenburg L, Hegerl U (2009) Gender issues in suicide rates, trends and methods among youths aged 15-24 in 15 European countries. J Affect Disord 13:216-226

32. Roberts C, Currie C, Samdal O, Currie D, Smith R, Maes L (2007) Measuring the health and health behaviours of adolescents through cross-national survey research: recent developments in the Health Behaviour in School-aged Children (HBSC) study. J Public Health 15:179-186

33. Currie C, Samdal O, Boyce W (2001) Health behaviour in schoolaged children: a World Health Organization cross-national Study Research Protocol for the 2001/2002 survey. Child and Adolescent Health Research Unit, University of Edinburgh, Edinburgh

34. Haugland S, Wold B (2001) Subjective health complaints in adolescence reliability and validity of survey methods. J Adolesc 24:611-624
35. Currie C, Molcho M, Boyce W, Holstein B, Torsheim T, Richter M (2008) Researching health inequalities in adolescents: the development of the Health Behaviour in School-Aged Children (HBSC) family affluence scale. Soc Sci Med 66:1429-1436

36. Richter M, Erhart M, Vereecken CA, Zambon A, Boyce W, Gabhainn SN (2009) The role of behavioural factors in explaining socio-economic differences in adolescent health: a multilevel study in 33 countries. Soc Sci Med 69:396-403

37. Torsheim T, Currie C, Boyce W, Kalnins I, Overpeck M, Haugland S (2004) Material deprivation and self-rated health: a multilevel study of adolescents from 22 European and North American countries. Soc Sci Med 59:1-12

38. Samm A, Varnik A, Tooding LM, Sisask M, Kolves K, von Knorring AL (2008) Children's depression inventory in Estonia. Single items and factor structure by age and gender. Eur Child Adolesc Psychiatry 17:162-170

39. Thomson E, Hanson TL, McLanahan SS (1994) Family structure and child well-being: economic resources vs. parental behaviors. Soc F 73:221-242

40. Verhulst FC, Van Der Ende JAN (1997) Factors associated with child mental health service use in the community. J Am Acad Child Adolesc Psychiatry 36:901-909

41. Garnefski N, Diekstra RFW (1997) Adolescents from one parent, stepparent and intact families: emotional problems and suicide attempts. J Adolesc 20:201-208

42. Hollis C (1996) Depression, family environment, and adolescent suicidal behavior. J Am Acad Child Adolesc Psychiatry 35:622630

43. Prinstein MJ, Boergers J, Spirito A, Little TD, Grapentine WL (2000) Peer functioning, family dysfunction, and psychological symptoms in a risk factor model for adolescent inpatients' suicidal ideation severity. J Clin Child Psychol 29:392-405

44. Reinherz HZ, Giaconia RM, Pakiz B, Silverman AB, Frost AK, Lefkowitz ES (1993) Psychosocial risks for major depression in late adolescence: a longitudinal community study. J Am Acad Child Adolesc Psychiatry 32:1155-1163

45. Kaslow NJ, Rehm LP, Siegel AW (1984) Social-cognitive and cognitive correlates of depression in children. J Abnorm Child Psychol 12:605-620

46. Ravens-Sieberer U, Torsheim T, Hetland J, Vollebergh W, Cavallo F, Jericek H, Alikasifoglu M, Välimaa R, Ottova V, Erhart M (2009) Subjective health, symptom load and quality of life of children and adolescents in Europe. Int J Public Health 54:151-159

47. Adams DM, Overholser JC, Lehnert K (1994) Perceived family functioning and adolescent suicidal behavior. J Am Acad Child Adolesc Psychiatry 33:498-507

48. Kennedy GE, Kennedy CE (1993) Grandparents: a special resource for children in stepfamilies. The stepfamily puzzle: intergenerational influences. Haworth Press Inc, NY

49. Steelman LC, Powell B, Werum R, Carter S (2002) Reconsidering the effects of sibling configuration: recent advances and challenges. Annu Rev Sociol 28:243-269

50. Blum RW, Beuhring T, Shew ML, Bearinger LH, Sieving RE, Resnick MD (2000) The effects of race/ethnicity, income, and family structure on adolescent risk behaviors. Am J Public Health 90:1879-1884

51. King RA, Schwab-Stone M, Flisher AJ, Greenwald S, Kramer RA, Goodman SH, Lahey BB, Shaffer D, Gould MS (2001) Psychosocial and risk behavior correlates of youth suicide attempts and suicidal ideation. J Am Acad Child Adolesc Psychiatry 40:837-846 